\title{
Causes and Consequences of Chronic Sleep Deficiency and the Role of Orexin
}

\author{
Janet M. Mullingtona Tony J. Cunningham ${ }^{\mathrm{b}, \mathrm{c}}$ Monika Haack ${ }^{\mathrm{a}}$ \\ Huan Yanga \\ a Department of Neurology, Beth Israel Deaconess Medical Center and Harvard Medical School, \\ Boston, MA, USA; ${ }^{b}$ Department of Psychiatry, Beth Israel Deaconess Medical Center and Harvard Medical School, \\ Boston, MA, USA; ' Department of Psychology and Neuroscience, Boston College, Boston, MA, USA
}

\begin{abstract}
Sleep is one of the pillars of health. Experimental models of acute sleep loss, of chronic partial sleep deprivation, and of sleep fragmentation in healthy sleepers are helpful models of sleep deficiency produced by insufficient sleep duration, sleep timing, and sleep disorders. Sleep deficiency is associated with changes in markers associated with risk for disease. These include metabolic, inflammatory, and autonomic markers of risk. In addition, sleep disruption and sleep deficits lead to mood instability, lack of positive outlook, and impaired neurobehavioral functioning. On a population level, insufficient sleep is associated with increased risk for hypertension and diabetes. Sleep disturbance is very common, and about half the population will report that they have experienced insomnia at some time in their lives. Approximately $10 \%$ of the population describe daytime impairment due to sleep disturbance at night, consistent with a diagnosis of insomnia disorder. The hypothalamic neuropeptides, orexin-A and orexin- $B$, act through G-protein-coupled receptors (orexin-1 and orexin-2 receptors). Dual and selective orexin-2 receptor antagonists have shown efficacy in inducing sleep in men and women with insomnia disorder by accelerating sleep onset and improving sleep efficiency and total sleep time. Further study comparing these medications, in short- and longer-term use models, is recommended. Greater understanding of comparative effects on mood, neurobehavioral, and physiological systems will help determine the extent of clinical utility of dual versus selective orexin receptor antagonists.
\end{abstract}

(C) 2021 The Author(s)

Published by S. Karger AG, Basel 


\section{Mood and Performance}

Every adult has experienced a night without good sleep, or even any sleep. This happens when we travel, or have work, family, or social obligations that cause us to cut back on sleep or to have poor quality sleep. This experience of inadequate sleep defines the importance of sleep, in the present, for all of us. The brain fog, the dragged down feeling, and the lack of energy and motivation or ability to do much of anything, the bodily discomfort and irritability, are all symptoms of insufficient or deficient sleep that most of us have experienced, at least transiently. Almost magically, when we get that quality sleep that we so badly need, we can feel rejuvenated and fully restored after even a single night. However, for some who struggle with insomnia symptoms, the ability to have consolidated restorative sleep recedes, and the insomnia becomes a chronic disorder. Understanding the importance of sleep for health and well-being in the longer-term, when sleep deficiency has become chronic, is complicated due to the multiplicity of effects of sleep loss on mood, cognitive function, and physiological systems.

Experimental studies have helped to parse the effects of deficient sleep on these systems, using surrogate markers of risk for adverse outcomes. In a study of acute total sleep deprivation and chronic partial sleep deprivation, where sleep was curtailed to half the normal amount for 14 days, there was a dose-dependent negative influence of sleep loss on neurobehavioral function, including psychomotor vigilance, digit symbol substitution, and the serial addition/subtraction task [1]. With respect to mood and subjective wellbeing, this study and others have shown that curtailment of sleep, to little more than half the usual amount (4-5 hours/night) for just 2 or 3 nights, resulted in decreased mood as well as decreased optimism and sociability indices, and increased fatigue and irritability $[2,3]$. Outside of the experimental setting, these findings appear to hold up. A study of first year medical residents found that risk for depression and perceived medical errors was associated with sleep disturbance and short sleep [4]. A meta-analysis of studies, which included 1,932 participants, found that mood was even more impaired by sleep loss than cognitive or motor performance [5]. Moreover, those who have chronically deficient sleep are at three times greater risk of developing depression, and even good sleepers are at double the risk if they regularly shorten their sleep [4]. Thus, in the short-term, deficiency in sleep causes difficulties in mood and emotion regulation, cognitive throughput and outlook, and in the longer-term, may lead to depression.

\section{Insomnia, Mood Regulation, and Orexin Receptor Antagonists}

The orexin system interacts with the hypothalamic-pituitary axis and the autonomic nervous system to modulate the stress response, wake and sleep, as well as to regulate metabolic and inflammatory systems. There are two peptides produced by cells in the lateral hypothalamus, orexin-A and orexin-B, and both stem from a common precursor polypeptide, prepro-orexin. The orexins activate two G-coupled receptors, orexin-1 receptor 
$\left(\mathrm{OX}_{1} \mathrm{R}\right)$ and orexin-2 receptor $\left(\mathrm{OX}_{2} \mathrm{R}\right) . \mathrm{OX}_{1} \mathrm{R}$ has higher affinity with orexin- $\mathrm{A}$ than $-\mathrm{B}$, but $\mathrm{OX}_{2} \mathrm{R}$ binds both orexins with similar affinities [6]. Research on the orexin system has been generated at a rapid rate since its discovery in 1998 [7], and discoveries on the mechanisms and function of this system remain on an increasing trajectory. It is now clear that orexins play a significant role in mood and sleep regulation, and that $\mathrm{OX}_{2} \mathrm{R}$ may be more specifically involved in sleep-wake regulation.

A dual receptor antagonist (DORA), suvorexant (Belsomra ${ }^{\mathrm{TM}}$, Merck \& Co. Inc.), received approval from the US Food and Drug Administration (FDA) for the treatment of insomnia in adults in 2014. Since then, the dual receptor antagonist, lemborexant (Davigo $^{\mathrm{TM}}$, Eisai Inc.), has been developed and subsequently, in 2019, received FDA approval for the treatment of insomnia. A new drug application for a third DORA, daridorexant (Idorsia Pharmaceuticals Ltd.) which showed improvement in sleep and daytime functioning in a Phase 3 clinical program [8], was submitted to the FDA in January 2021. To date, there have been no head-to-head studies comparing the different DORAs; however, there are a number of studies that have investigated the effects of these drugs on sleep architecture $[6,9]$. In short, in clinical studies, the DORAs reduce time to persistent sleep, increase total sleep time, increase sleep efficiency, and increase non-rapid eye movement (NREM) and rapid eye movement (REM) sleep [10-13].

It can be challenging to evaluate treatments for insomnia because the complaint is a subjective one. An estimated 50\% of patients who suffer from insomnia do not have objectively deficient sleep and, in fact, get at least 7-8 h of sleep/night, an amount of sleep recommended for health maintenance [14]. The stress and distress of the experience of deficient sleep is, therefore, separable from the measurable physiological characteristics. The physiological consequences of insufficient sleep can be measured in controlled studies of healthy volunteers who undergo experimental procedures that reduce or disrupt sleep. While psychological stress is certainly an important health modifier itself, studies have shown that patients with insomnia and short sleep have more deleterious health outcomes, thus, interventions that can safely and sustainably increase sleep duration are clearly needed.

\section{Sleep Deficiency and Metabolic and Neuroendocrine Outcomes}

An accumulation of experimental research has demonstrated, in healthy volunteers with subjectively and objectively assessed good sleep, that short and disrupted sleep affects endocrine and metabolic, autonomic and cardiovascular, and immune systems [15-17]. Acute total sleep deprivation studies have been used to investigate the role of sleep in regulating these systems. Stable placement of the sleep period in circadian time helps to anchor the circadian rhythms of several key hormones that regulate physiological systems and functions [18]. The pineal hormone, melatonin, increases during the onset of dim light to peak at night during sleep; it is inhibited by bright light, but has a strong circadian rhythm showing decline before time of normal rising. Hypothalamic anterior pituitary 
hormones are strongly modulated by sleep and wakefulness. Human growth hormone pulsatile secretion typically peaks during the first cycle of NREM sleep (approximately $70 \%$ of the 24 -h secretion in men) [19]. If wakefulness is sustained through the night, that normal nocturnal peak pulse of human growth hormone is blunted or eliminated. Further, the diurnal rhythm of cortisol that tends to reach its nadir about half an hour after sleep onset, is elevated.

The first study showing short-term clinical outcomes directly attributable to an endocrine challenge of sleep deficiency was a controlled sleep restriction study published in the Lancet in 1999 [20]. This study found that sleeping $4 \mathrm{~h}$ per night for 6 nights led to slowed glucose metabolism. Since then, numerous physiological studies have shown that insufficient sleep duration and quality compromise metabolic functioning. These studies have been conducted in healthy volunteers and have shown that sleep restriction, as is commonly encountered in everyday life, such as exposure to $5 \mathrm{~h}$ per night for 1 week [21], significantly reduces insulin sensitivity. This effect seems to be most dependent on slowwave sleep, as disruption of that phase of sleep leads to reduced insulin sensitivity without changes in insulin release [22]. These physiological studies were corroborated by population studies that examined the association of sleep duration and risk for becoming overweight or developing diabetes and identified deficient sleep as a major contributing risk factor for diabetes and decreased glucose tolerance [23].

Orexin is not only found in the brain but is also one of the peptides found in the enteric nervous system, and evidence suggests that it is important for appetite and regulation of feeding and glucose homeostasis [24, 25]. Moreover, sleep disturbance is associated with upper and lower gastrointestinal symptoms in the general population [26], and orexin-A has been proposed as a possible treatment for inflammatory and anxiety-related diseases such as irritable bowel syndrome [27]. Certainly, there are grounds for investigation of the metabolic and endocrine modulating effects of the orexin receptor antagonists used in treatment for insomnia.

\section{Autonomic Control by Sleep and Consequences of Insufficient Sleep}

It was first discovered that blood pressure (BP) and heart rate drop precipitously during sleep in 1975 [28]. Eighteen years later, Somers et al. [29] showed that sympathetic activity decreased during NREM sleep and increased during REM sleep and wakefulness. In fact, shortly before the onset of a period of slow-wave sleep, there is a spike peak in the normalized high frequency of the RR interval in the electrocardiographic signal [30].

When healthy sleepers go without sleep for a night, their BP, arterial stiffness, and heart rate are increased, and parasympathetic activity decreased [31-33]. Sleep loss models of chronic sleep restriction, involving several days restricted to about half of the normal amount of sleep, have confirmed the sleep control of autonomic functions, showing increased BP and decreased nocturnal BP dipping [34], and report that baroreflex sensitivity changes and rebounds when sleep is resumed [35]. The sleep loss-associated changes 
may be, in part, due to renal changes [34], and in part due to altered endothelial function $[36,37]$.

Epidemiological research has identified insomnia as a risk factor for cardiovascular disease $[38,39]$, and it is known that the cardiovascular consequences of insomnia are particularly evident in patients with objective short sleep duration [40]. It is likely that more than half the population of insomnia disorder patients have objective short sleep of less than $6 \mathrm{~h}$ per night [40]. Insomnia with short sleep is associated with worse performance on neuropsychological tests commonly used in clinical practice [41], suggesting that deficient sleep may be a factor contributing to cognitive impairment in aging.

Population-based research has confirmed the association between short sleep and risk for hypertension [42], and studies have begun to look at sleep as an intervention. One promising behavioral intervention pilot study found that extending the bed period increased sleep duration and lowered BP in a group of pre-hypertensive and stage- 1 hypertensive patients [43]. Current studies are underway to investigate the efficacy of sleep extension and sleep period stabilization in circadian time as behavioral interventions to lower BP (ClinicalTrials, gov identifier: NCT03043963 J. Mullington, principal investigator [PI] and NCT02929810, V. Somers, PI).

In 2003, it was reported that the cardiovascular response to stress in the orexin knockout mouse model was diminished [44]. This finding was later corroborated by showing that DORAs also reduce the cardiovascular stress response [45]. Research since that time has found the interactions between the orexin system and autonomic control to be quite complicated, involving receptors in a number of brain areas. The orexin-A system is involved in regulating stress-related $\mathrm{BP}$ increases [46]. $\mathrm{OX}_{1} \mathrm{R}$ and $\mathrm{OX}_{2} \mathrm{R}$ mediate increased $\mathrm{BP}$ and heart rate in the dorsomedial hypothalamus [47]. In an animal model of genetically predisposed hypertension, Jackson et al. [48] found that these mice have almost 30\% more orexin-expressing neurons in the lateral hypothalamus than a wild-type-like control, and further, their BP and heart rate were decreased by the DORA almorexant during the dark (active) period.

While there is little data published on the orexin control of BP in healthy human sleepers, patients with narcolepsy have reduced orexin neurons and orexin-A levels in cerebrospinal fluid (CSF) [49-51]. While one might expect that the low levels of orexin in narcolepsy would protect these patients from hypertension, they do not, signifying a complex relationship. Patients who have narcolepsy are in fact at increased risk for multiple diagnoses, both before and after the diagnosis of narcolepsy, and these include hypertension and cardiovascular disease [52]. In a study of untreated patients with narcolepsy type 1 (narcolepsy with cataplexy), there was an increased likelihood of diastolic non-dipping status (where patients had less than $10 \%$ drop in BP at night) in approximately $31 \%$ compared with only $3 \%$ in healthy control subjects [53]. However, in a study investigating orexin and BP dipping in narcolepsy type 1, there was no relationship between presence or absence of detectable CSF orexin and dipping status [54]. Still, Sorensen et al. [55] found that, in narcolepsy, the heart rate response to arousal in REM and NREM sleep is reduced and related to orexin-A deficiency. 
REM sleep-deprived rats show increased orexin-A in several brain regions [56]. In genetically atherosclerosis-prone mice, orexin-A levels in the hypothalamus, plasma, and bone marrow were reduced by experimental sleep fragmentation [57]. After prolonged experimental sleep restriction in humans, CSF orexin concentrations have been found to increase [58]. While research into the relationship between the autonomic system, inflammation, sleep and the orexin system is in early development, this intersection of systems warrants further investigation.

\section{Pain and Sleep Deficiency}

Studies in humans have shown that not only does pain disrupt sleep, but conditions producing sleep deficiency induce pain [for review, see 59]. In the general population, sleep deficiency predicts chronic pain risk [60]. For example, in an adult working population, a diagnosis of insomnia predicted the incidence of headache, osteoarthritis, rheumatoid arthritis, or fibromyalgia, 11 years later [61]. In controlled experimental studies, sleep restriction or disruption increased spontaneous pain complaints [62-64]. A number of studies on the effects of shortened or disrupted sleep have also reported elevated sensitivity to pain, as indicated by lowered pain thresholds to heat or pressure [65-69]. Pain is controlled by central, top-down pain-inhibitory and -facilitatory circuits, which can reduce or increase the intensity of a sensation [70]. Dysfunctions of these central pain-modulatory systems determine whether pain becomes chronic [71]. A few research studies have shown that short or disrupted sleep affects pain-modulatory pathways. In the first study conducted on the effects of sleep disruption on pain modulation, 2 nights of experimentally disrupted sleep resulted in less efficient pain-inhibitory circuits [64]. In a model of chronic short sleep where participants were exposed to 3 "weeks" of experimentally controlled short sleep of $4 \mathrm{~h}$ per night for 5 nights followed by 2 nights of recovery sleep, short sleep progressively decreased the ability to habituate to pain [68]. This finding reflects reduced efficient pain-inhibitory function. This study also found that pro- and counter inflammatory systems (IL-6 expression by monocytes, cortisol in blood) were upregulated due to chronic sleep restriction [72] and remained elevated after 2 nights of recovery sleep. These data suggest that the common pattern of sleeping short during the week and attempting to catch up on lost sleep on the weekend is not an effective strategy for mitigating the immunomodulatory deficits associated with insufficient sleep. Such immunomodulatory responses to sleep deficiency likely contribute to increased infection risk and impaired antibody responses to vaccinations that have been repeatedly reported in individuals with short or disturbed sleep. For example, in the presence of elevated inflammatory markers, certain immune cells are less sufficient in their defense against viruses and other pathogens (reviewed in [73]). In patients with insomnia disorder, who are otherwise healthy, daily spontaneous pain is reported with double the frequency of good sleepers, and during experimental pain testing, these patients have reduced pain thresholds and show a marked impairment of pain-inhibitory circuits [74]. 
Orexin neurons project widely with direct connection to vagal and hypothalamic pituitary stress regulatory systems. Orexin neurons project from the lateral hypothalamus to brain regions including the periaqueductal gray, a key brain structure in pain modulation, as well as the dorsal horn of the spinal cord [75]. These connections are evidence of its broad involvement in multiple physiological regulating systems, including nociception. In animal models of injury and inflammation, intrathecally administered orexin-A is analgesic, and this analgesic effect can be blocked by an $\mathrm{OX}_{1} \mathrm{R}$ antagonist [76]. Thus, there is evidence that the $\mathrm{OX}_{1} \mathrm{R}$ receptor plays a role in analgesia.

\section{Conclusions and Future Directions}

Sleep is a pillar of health, of critical importance for the regulation of mood, metabolic and neuroendocrine physiology, autonomic and pain systems. Sleep is essential for the sustainment of health and homeostatic functions. The discovery of orexin, a peptide central to the maintenance of wakefulness and response to stressors, has been a major breakthrough for research into the regulation of sleep and wakefulness [7, 77]. The orexin system, through its central modulation of stress-responding mechanisms and activation-deactivation of alertness, also plays a role in host defense mechanisms. Research in animal models has demonstrated that orexin- $A$ and $-B$, and their receptors 1 and 2 are powerful mediators of arousal, stress, autonomic and metabolic function. Improvement in methods and compounds designed to better target brain centers, receptors, agonists and antagonists are needed and will help move research on the mechanism of action forward.

The problem of sleep deficiency and insomnia represents an urgent unmet public health need, one that research will help solve. While cognitive behavioral therapy for insomnia is a successful approach to treatment, it has limitations, particularly in the acute illness setting [78]. Patients hospitalized frequently need sleep aids due to the lighting, noise, and treatment schedules. Patients struggling to recover from addiction relapse, due in part to the inability to sleep. Studies are currently underway in this area. A sleep aid that would help restore safe sleep without promoting dependence or grogginess upon waking would be of great benefit in health care, as well as for use in insomnia disorder.

Insomnia with short sleep is a risk factor for depression and for metabolic and cardiovascular disease. Safe interventions would have great value to ensure that sleep may be obtained when needed, and in the longer-term, could reduce disease risk. Orexin receptor antagonists may have beneficial effects through direct and indirect effects on sleep and may be helpful in mitigating effects of sleep loss on many regulatory functions. Longerterm clinical research will be needed to evaluate the potential benefit of these pharmacological interventions for reducing insufficient sleep-associated disease risk markers and for improving health maintenance. 


\section{Key Take-Home Points}

- Sleep deficiency leads to impairment in daytime neurobehavioral functioning.

- Reduction of sleep duration by $50 \%$ even for a couple of days has negative effects on mood and sociability.

- Sleep deficiency increases markers of risk for metabolic and cardiovascular disease.

- Sleep deficiency impairs central pain-modulatory functions, which are involved in the pathopysiology of chronic pain.

\section{Conflict of Interest Statement}

J.M.M. received consultancy fees from Idorsia Pharmaceuticals Ltd. during the development of this book. The authors have no other conflicts of interest to declare.

\section{Funding Sources}

The authors have no funding to declare.

\section{Author Contributions}

All authors were involved in the development and review of the chapter, approved the final version, and take responsibility for all aspects of the work.

\section{References}

1 Van Dongen HP, Maislin G, Mullington JM, Dinges DF: The cumulative cost of additional wakefulness: doseresponse effects on neurobehavioral functions and sleep physiology from chronic sleep restriction and total sleep deprivation. Sleep 2003;26:117-126.

2 Dinges DF, Pack F, Williams K, Gillen KA, Powell JW, Ott GE, et al: Cumulative sleepiness, mood disturbance, and psychomotor vigilance performance decrements during a week of sleep restricted to $4-5 \mathrm{~h}$ per night. Sleep 1997;20:267-277.

3 Haack M, Mullington JM: Sustained sleep restriction reduces emotional and physical well-being. Pain 2005; 119:56-64.

4 Kalmbach DA, Arnedt JT, Song PX, Guille C, Sen S: Sleep disturbance and short sleep as risk factors for depression and perceived medical errors in first-year residents. Sleep 2017;40:zsw073.

5 Pilcher JJ, Huffcutt AI: Effects of sleep deprivation on performance: a meta-analysis. Sleep 1996;19:318-326.

6 Muehlan C, Vaillant C, Zenklusen I, Kraehenbuehl S, Dingemanse J: Clinical pharmacology, efficacy, and safety of orexin receptor antagonists for the treatment of insomnia disorders. Expert Opin Drug Metab Toxicol 2020;16:1063-1078.
7 de Lecea L, Kilduff TS, Peyron C, Gao X, Foye PE, Danielson PE, et al: The hypocretins: hypothalamus-specific peptides with neuroexcitatory activity. Proc Natl Acad Sci USA 1998;95:322-327.

8 Roth T, Zammit G, Mignot E, Leger D, Bassetti C, Pain S, et al: P167. Daridorexant, a novel dual orexin receptor antagonist, delivers significant improvement in sleep parameters and daytime function for patients with insomnia disorder. J Sleep Res 2020;29(S1):e13181.

9 Clark JW, Brian ML, Drummond SPA, Hoyer D, Jacobson LH: Effects of orexin receptor antagonism on human sleep architecture: a systematic review. Sleep Med Rev 2020;53:101332.

10 Bonaventure P, Shelton J, Yun S, Nepomuceno D, Sutton S, Aluisio L, et al: Characterization of JNJ-42847922, a selective orexin-2 receptor antagonist, as a clinical candidate for the treatment of insomnia. J Pharmacol Exp Ther 2015;354:471-482.

11 Gotter AL, Forman MS, Harrell CM, Stevens J, Svetnik $\mathrm{V}$, Yee KL, et al: Orexin 2 receptor antagonism is sufficient to promote NREM and REM sleep from mouse to man. Sci Rep 2016;6:27147. 
12 Brooks S, Jacobs GE, de Boer P, Kent JM, Van Nueten L, van Amerongen G, et al: The selective orexin-2 receptor antagonist seltorexant improves sleep: an exploratory double-blind, placebo controlled, crossover study in antidepressant-treated major depressive disorder patients with persistent insomnia. J Psychopharmacol 2019;33:202-209.

13 De Boer P, Drevets WC, Rofael H, van der Ark P, Kent JM, Kezic I, et al: A randomized Phase 2 study to evaluate the orexin-2 receptor antagonist seltorexant in individuals with insomnia without psychiatric comorbidity. J Psychopharmacol 2018;32:668-677.

14 Watson NF, Badr MS, Belenky G, Bliwise DL, Buxton OM, Buysse D, et al: Joint consensus statement of the American Academy of Sleep Medicine and Sleep Research Society on the recommended amount of sleep for a healthy adult: methodology and discussion. J Clin Sleep Med 2015;11:931-952.

15 Anothaisintawee T, Reutrakul S, Van Cauter E, Thakkinstian A: Sleep disturbances compared to traditional risk factors for diabetes development: systematic review and meta-analysis. Sleep Med Rev 2016;30:11-24.

16 Besedovsky L, Lange T, Haack M: The sleep-immune crosstalk in health and disease. Physiol Rev 2019;99: 1325-1380.

17 Mullington JM, Simpson NS, Meier-Ewert HK, Haack M: Sleep loss and inflammation. Best Pract Res Clin Endocrinol Metab 2010;24:775-784.

18 Morris CJ, Purvis TE, Hu K, Scheer FA: Circadian misalignment increases cardiovascular disease risk factors in humans. Proc Natl Acad Sci USA 2016;113:E1402E1411.

19 Van Cauter E, Plat L: Physiology of growth hormone secretion during sleep. J Pediatr 1996;128(5 Pt 2):S32S37.

20 Spiegel K, Leproult R, Van Cauter E: Impact of sleep debt on metabolic and endocrine function. Lancet 1999; 354:1435-1439.

21 Buxton OM, Pavlova M, Reid EW, Wang W, Simonson DC, Adler GK: Sleep restriction for 1 week reduces insulin sensitivity in healthy men. Diabetes 2010;59:21262133.

22 Tasali E, Leproult R, Ehrmann DA, Van Cauter E: Slowwave sleep and the risk of type 2 diabetes in humans. Proc Natl Acad Sci USA 2008;105:1044-1049.

23 Gangwisch JE, Heymsfield SB, Boden-Albala B, Buijs RM, Kreier F, Pickering TG, et al: Sleep duration as a risk factor for diabetes incidence in a large U.S. sample. Sleep 2007;30:1667-1673.

24 Ehrström M, Gustafsson T, Finn A, Kirchgessner A, Grybäck P, Jacobsson H, et al: Inhibitory effect of exogenous orexin a on gastric emptying, plasma leptin, and the distribution of orexin and orexin receptors in the gut and pancreas in man. J Clin Endocrinol Metab 2005; 90:2370-2377.

25 Rani M, Kumar R, Krishan P: Role of orexins in the central and peripheral regulation of glucose homeostasis: evidences \& mechanisms. Neuropeptides 2018;68:1-6.
26 Cremonini F, Camilleri M, Zinsmeister AR, Herrick LM, Beebe T, Talley NJ: Sleep disturbances are linked to both upper and lower gastrointestinal symptoms in the general population. Neurogastroenterol Motil 2009;21:128135.

27 Mediavilla C: Bidirectional gut-brain communication: a role for orexin-A. Neurochem Int 2020;141:104882.

28 Littler WA, Honour AJ, Carter RD, Sleight P: Sleep and blood pressure. BMJ 1975;3:346-348.

29 Somers VK, Dyken ME, Mark AL, Abboud FM: Sympathetic-nerve activity during sleep in normal subjects. $\mathrm{N}$ Engl J Med 1993;328:303-307.

30 Jurysta F, van de Borne P, Migeotte PF, Dumont M, Lanquart JP, Degaute JP, et al: A study of the dynamic interactions between sleep EEG and heart rate variability in healthy young men. Clin Neurophysiol 2003;114: 2146-2155.

31 Sunbul M, Kanar BG, Durmus E, Kivrak T, Sari I: Acute sleep deprivation is associated with increased arterial stiffness in healthy young adults. Sleep Breath 2014;18: 215-220.

32 Yang H, Durocher JJ, Larson RA, Dellavalla JP, Carter JR: Total sleep deprivation alters cardiovascular reactivity to acute stressors in humans. J Appl Physiol (1985) 2012;113:903-908.

33 Zhong X, Hilton HJ, Gates GJ, Jelic S, Stern Y, Bartels $\mathrm{MN}$, et al: Increased sympathetic and decreased parasympathetic cardiovascular modulation in normal humans with acute sleep deprivation. J Appl Physiol (1985) 2005;98:2024-2032.

34 Yang H, Haack M, Gautam S, Meier-Ewert HK, Mullington JM: Repetitive exposure to shortened sleep leads to blunted sleep-associated blood pressure dipping. J Hypertens 2017;35:1187-1194.

35 Yang H, Haack M, Dang R, Gautam S, Simpson NS, Mullington JM: Heart rate variability rebound following exposure to persistent and repetitive sleep restriction. Sleep 2019;42:zsy226.

36 Calvin AD, Covassin N, Kremers WK, Adachi T, Macedo $\mathrm{P}$, Albuquerque FN, et al: Experimental sleep restriction causes endothelial dysfunction in healthy humans. J Am Heart Assoc 2014;3:e001143.

37 Sauvet F, Leftheriotis G, Gomez-Merino D, Langrume C, Drogou C, Van Beers P, et al: Effect of acute sleep deprivation on vascular function in healthy subjects. J Appl Physiol (1985) 2010;108:68-75.

38 Schwartz SW, Cornoni-Huntley J, Cole SR, Hays JC, Blazer DG, Schocken DD: Are sleep complaints an independent risk factor for myocardial infarction? Ann Epidemiol 1998;8:384-392.

39 Sofi F, Cesari F, Casini A, Macchi C, Abbate R, Gensini GF: Insomnia and risk of cardiovascular disease: a metaanalysis. Eur J Prev Cardiol 2014;21:57-64.

40 Vgontzas AN, Liao D, Bixler EO, Chrousos GP, VelaBueno A: Insomnia with objective short sleep duration is associated with a high risk for hypertension. Sleep 2009;32:491-497. 
41 Fernandez-Mendoza J, He F, Puzino K, Amatrudo G, Calhoun S, Liao D, et al: Insomnia with objective short sleep duration is associated with cognitive impairment: a first look at cardiometabolic contributors to brain health. Sleep 2021;44:zsaa150.

42 Gangwisch JE, Heymsfield SB, Boden-Albala B, Buijs RM, Kreier F, Pickering TG, et al: Short sleep duration as a risk factor for hypertension: analyses of the first National Health and Nutrition Examination Survey. Hypertension 2006;47:833-839.

43 Haack M, Serrador J, Cohen D, Simpson N, Meier-Ewert $\mathrm{H}$, Mullington JM: Increasing sleep duration to lower beat-to-beat blood pressure: a pilot study. J Sleep Res 2013;22:295-304.

44 Kayaba Y, Nakamura A, Kasuya Y, Ohuchi T, Yanagisawa M, Komuro I, et al: Attenuated defense response and low basal blood pressure in orexin knockout mice. Am J Physiol Regul Integr Comp Physiol 2003; 285:R581-R593.

45 Furlong TM, Vianna DM, Liu L, Carrive P: Hypocretin/ orexin contributes to the expression of some but not all forms of stress and arousal. Eur J Neurosci 2009;30: 1603-1614.

46 Kuwaki T: Orexin links emotional stress to autonomic functions. Auton Neurosci 2011;161:20-27.

47 Li TL, Chen JYS, Huang SC, Dai YE, Hwang LL: Cardiovascular pressor effects of orexins in the dorsomedial hypothalamus. Eur J Pharmacol 2018;818:343-350.

48 Jackson KL, Dampney BW, Moretti JL, Stevenson ER, Davern PJ, Carrive P, et al: Contribution of orexin to the neurogenic hypertension in $\mathrm{BPH} / 2 \mathrm{~J}$ mice. Hypertension 2016;67:959-969.

49 Nishino S, Ripley B, Overeem S, Lammers GJ, Mignot E: Hypocretin (orexin) deficiency in human narcolepsy. Lancet 2000;355:39-40.

50 Peyron C, Faraco J, Rogers W, Ripley B, Overeem S, Charnay Y, et al: A mutation in a case of early onset narcolepsy and a generalized absence of hypocretin peptides in human narcoleptic brains. Nat Med 2000;6: 991-997.

51 Thannickal TC, Moore RY, Nienhuis R, Ramanathan L, Gulyani S, Aldrich M, et al: Reduced number of hypocretin neurons in human narcolepsy. Neuron 2000;27: 469-474.

52 Jennum P, Thorstensen EW, Pickering L, Ibsen R, Kjellberg J: Morbidity and mortality of middle-aged and elderly narcoleptics. Sleep Med 2017;36:23-28.

53 Dauvilliers Y: Altered sleep-related blood pressure profile in hypocretin-deficient narcoleptic patients. Sleep 2012;35:453-454.

54 Sieminski M, Chwojnicki K, Sarkanen T, Partinen M: The relationship between orexin levels and blood pressure changes in patients with narcolepsy. PLoS One 2017;12:e0185975.

55 Sorensen GL, Knudsen S, Petersen ER, Kempfner J, Gammeltoft S, Sorensen HB, et al: Attenuated heart rate response is associated with hypocretin deficiency in patients with narcolepsy. Sleep 2013;36:91-98.
56 Mehta R, Khanday MA, Mallick BN: REM sleep loss associated changes in orexin-A levels in discrete brain areas in rats. Neurosci Lett 2015;590:62-67.

57 McAlpine CS, Kiss MG, Rattik S, He S, Vassalli A, Valet C, et al: Sleep modulates haematopoiesis and protects against atherosclerosis. Nature 2019;566:383-387.

58 Olsson M, Ärlig J, Hedner J, Blennow K, Zetterberg H: Sleep deprivation and cerebrospinal fluid biomarkers for Alzheimer's disease. Sleep 2018;41.

59 Haack M, Simpson N, Sethna N, Kaur S, Mullington J: Sleep deficiency and chronic pain: potential underlying mechanisms and clinical implications. Neuropsychopharmacology 2020;45:205-216.

60 Afolalu EF, Ramlee F, Tang NKY: Effects of sleep changes on pain-related health outcomes in the general population: a systematic review of longitudinal studies with exploratory meta-analysis. Sleep Med Rev 2018;39:8297.

61 Sivertsen B, Lallukka T, Salo P, Pallesen S, Hysing M, Krokstad S, et al: Insomnia as a risk factor for ill health results from the large population-based prospective HUNT Study in Norway. J Sleep Res 2014;23:124-132.

62 Haack M, Sanchez E, Mullington JM: Elevated inflammatory markers in response to prolonged sleep restriction are associated with increased pain experience in healthy volunteers. Sleep 2007;30:1145-1152.

63 Haack M, Lee E, Cohen DA, Mullington JM: Activation of the prostaglandin system in response to sleep loss in healthy humans: potential mediator of increased spontaneous pain. Pain 2009;145:136-141.

64 Smith MT, Edwards RR, McCann UD, Haythornthwaite JA: The effects of sleep deprivation on pain inhibition and spontaneous pain in women. Sleep 2007;30:494505.

65 Iacovides S, George K, Kamerman P, Baker FC: Sleep fragmentation hypersensitizes healthy young women to deep and superficial experimental pain. J Pain 2017;18: 844-854.

66 Onen SH, Alloui A, Gross A, Eschallier A, Dubray C: The effects of total sleep deprivation, selective sleep interruption and sleep recovery on pain tolerance thresholds in healthy subjects. J Sleep Res 2001;10:35-42.

67 Roehrs T, Hyde M, Blaisdell B, Greenwald M, Roth T: Sleep loss and REM sleep loss are hyperalgesic. Sleep 2006;29:145-151.

68 Simpson NS, Scott-Sutherland J, Gautam S, Sethna N, Haack M: Chronic exposure to insufficient sleep alters processes of pain habituation and sensitization. Pain 2018;159:33-40.

69 Smith MT Jr, Remeniuk B, Finan PH, Speed TJ, Tompkins DA, Robinson M, et al: Sex differences in measures of central sensitization and pain sensitivity to experimental sleep disruption: implications for sex differences in chronic pain. Sleep 2019;42:zsy209.

70 Ossipov MH, Dussor GO, Porreca F: Central modulation of pain. J Clin Invest 2010;120:3779-3787.

71 Ossipov MH, Morimura K, Porreca F: Descending pain modulation and chronification of pain. Curr Opin Support Palliat Care 2014;8:143-151. 
72 Simpson NS, Diolombi M, Scott-Sutherland J, Yang H, Bhatt V, Gautam S, et al: Repeating patterns of sleep restriction and recovery: do we get used to it? Brain Behav Immun 2016;58:142-151.

73 Besedovsky L, Lange T, Haack M. The sleep-immune crosstalk in health and disease. Physiol Rev 2019;99(3):1325-80.

74 Haack M, Scott-Sutherland J, Santangelo G, Simpson NS, Sethna N, Mullington JM: Pain sensitivity and modulation in primary insomnia. Eur J Pain 2012;16:522533.

75 Ho YC, Lee HJ, Tung LW, Liao YY, Fu SY, Teng SF, et al: Activation of orexin 1 receptors in the periaqueductal gray of male rats leads to antinociception via retrograde endocannabinoid (2-arachidonoylglycerol)-induced disinhibition. J Neurosci 2011;31:14600-14610.
76 Razavi BM, Hosseinzadeh H: A review of the role of orexin system in pain modulation. Biomed Pharmacother 2017;90:187-193.

77 Sakurai T, Amemiya A, Ishii M, Matsuzaki I, Chemelli $\mathrm{RM}$, Tanaka H, et al: Orexins and orexin receptors: a family of hypothalamic neuropeptides and $\mathrm{G}$ proteincoupled receptors that regulate feeding behavior. Cell 1998;92:573-585.

78 Pisani MA, Friese RS, Gehlbach BK, Schwab RJ, Weinhouse GL, Jones SF. Sleep in the Intensive Care Unit. Am J Respir Crit Care Med 2015;191:731-8.

Janet M. Mullington

Beth Israel Deaconess Medical Center

330 Brookline Avenue

Boston, MA 02215 (USA)

jmulling@bidmc.harvard.edu 